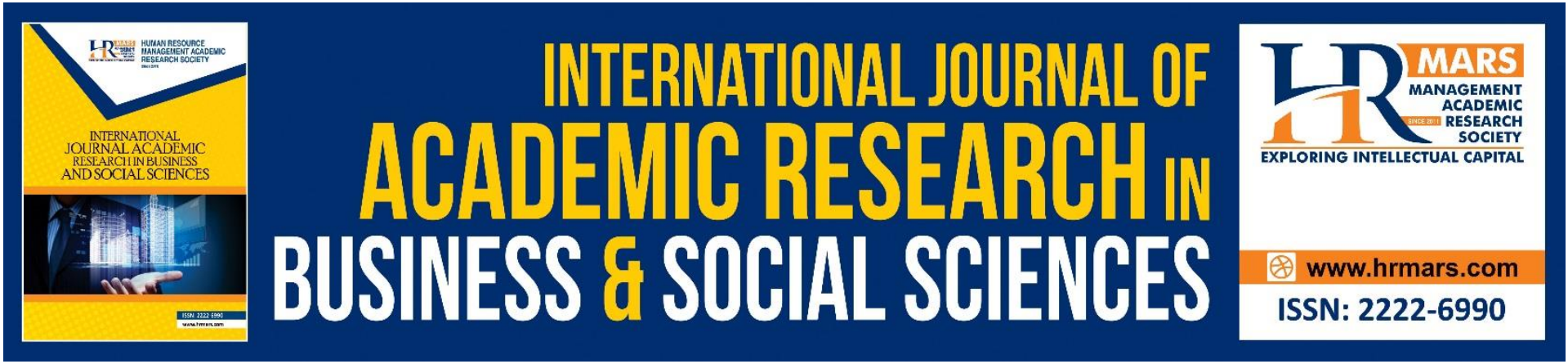

\title{
Passive Exoskeleton Safety Jacket for Use in Construction Projects
}

\section{Muhammad Redza Rosman \& Nurul Syafiqah Mahmud}

To Link this Article: http://dx.doi.org/10.6007/IJARBSS/v11-i5/9893

DOI:10.6007/IJARBSS/v11-i5/9893

Received: 14 March 2021, Revised: 16 April 2021, Accepted: 04 May 2021

Published Online: 15 May 2021

In-Text Citation: (Rosman \& Mahmud, 2021)

To Cite this Article: Rosman, M. R., \& Mahmud, N. S. (2021). Passive Exoskeleton Safety Jacket for Use in Construction Projects. International Journal of Academic Research in Business and Social Sciences, 11(5), 190-210.

\section{Copyright: @ 2021 The Author(s)}

Published by Human Resource Management Academic Research Society (www.hrmars.com)

This article is published under the Creative Commons Attribution (CC BY 4.0) license. Anyone may reproduce, distribute, translate and create derivative works of this article (for both commercial and non-commercial purposes), subject to full attribution to the original publication and authors. The full terms of this license may be seen at: http://creativecommons.org/licences/by/4.0/legalcode

Vol. 11, No. 5, 2021, Pg. 190 - 210

Full Terms \& Conditions of access and use can be found at http://hrmars.com/index.php/pages/detail/publication-ethics 


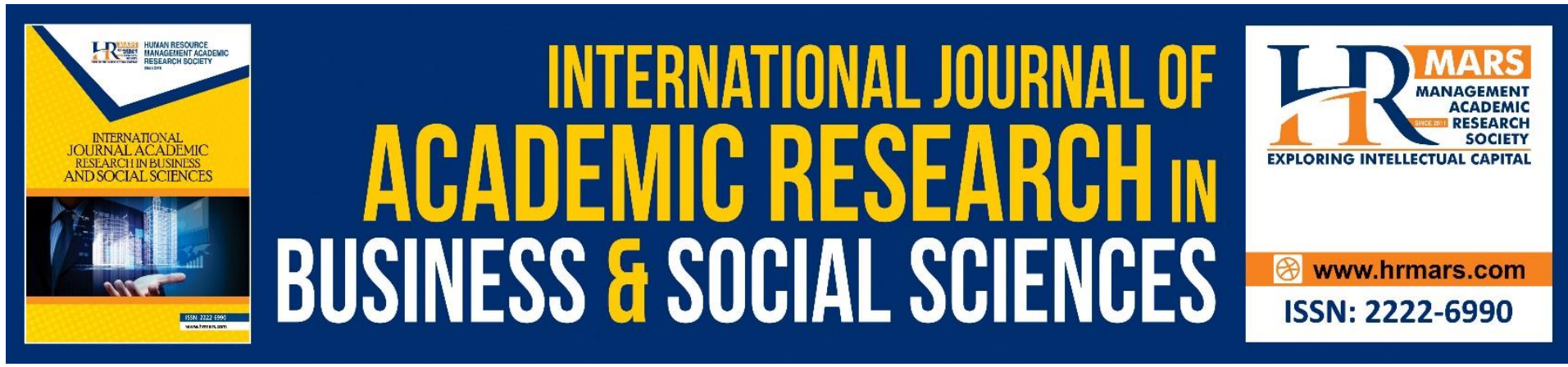

\title{
Passive Exoskeleton Safety Jacket for Use in Construction Projects
}

\author{
Muhammad Redza Rosman \& Nurul Syafiqah Mahmud
}

Centre of Studies for Construction, Department of Built Environment Studies and Technology, Universiti Teknologi MARA Perak Branch, Seri Iskandar Campus, 32610 Seri Iskandar, Perak, Malaysia

\begin{abstract}
Current research and statistical data show that safety wear innovations in construction especially in Malaysia are lagging behind other areas in the aspects of productivity, efficiency, and health, for which lack of innovation is to be blamed. This paper intends to illustrate the present status of construction innovation on safety and health wearables and the present statistics on Musculoskeletal Disorder diseases based on a review of current literature and research. This paper also aims to raise awareness on the Musculoskeletal Disease (MSD) among manufacturing and construction and civil workers in Malaysia and tackle the problems by doing immediate innovation to prevent cases of MSD from increasing year by year. This paper also aims to elaborate on the innovation concept of a skeletal safety jacket. A methodology has been developed to make sure that the objectives of this innovation are achieved. Literature review and desk studies have been done to collect the data.
\end{abstract}

Keywords: Exoskeleton, Safety Jacket, Musculoskeletal Disease (MSD)

\section{Introduction}

\section{Background of Study}

Most of the people tend to relate the construction industry with a dangerous working environment and high risk as compared to others (Mohd et al. 2007). International Labor Organization (ILO) reported that two million workers died every year because of occupational injuries and accidents (ILO, 2000). According to the United States Public Health Service, the construction industry was identified as one of the significant contributors to the highest rate of WMSDs associated with Cumulative Trauma Disorders (CTD) and lower back pain (Stavenich \& Hsio, 1996). The recent record of cases in Malaysia that were reported by the Social Security Organization (SOCSO) shows a tremendous increase of Musculoskeletal Disease (MSD) cases from 10 in 2005 to 675 in 2014 (SOCSO, 2015). A demographic analysis carried out shows that the occurrence of MSDs is highest (51.72\%) among industrial manufacturing workers here in Malaysia compared to the other industries (Affandi et al. 2012).

Despite all these hazards and accidents record, the degree of safety awareness and workers' emotional health is still low among the industry players. Until today, there are yet to be any innovations that can cater to these health problems. 


\section{Problem Identification}

MSDs cause harm and suffering to the workers and have an enormous negative impact on society. At the workplace level, the disorder results in increased production cost due to reduced human capacity and disturbance to productions. The costs to society are increased due to the need for treatment and rehabilitation, in addition to the compensation costs paid through social insurances. The cases of MSD among the construction workers have been increasing year by year. This is due to the heavy load and repetitive works that were executed by the workers. The recent innovation that was introduced is not suitable to be used in Malaysia.

\section{Aim \& Objectives}

This research aims to enhance the current wearable technology with the latest technology application, by seeking to identify and review the effect of MSDs to the construction and manufacturing workers and the current thru wearables technology in construction industry thru literature review and journal article, to propose a new innovation idea on improving the health and safety in the construction and manufacturing industry, and to evaluate the marketability of the proposed innovation product to the potential user.

\section{Literature Review Wearables Technologies}

Theoretically, wearables can be defined as a new type of human-computer interaction through the concept of simply holding portable compact computing devices (Choi, Hwang, \& Lee, 2017). Wearable technology is also a category of technology devices that can be worn by a consumer and often include tracking information related to health and fitness. Others might have small sensors to synchronize the data with mobile devices. Wearable technology assigns the attributes of mobility and connectivity to users so that users can access online information conveniently and communicate with others immediately while moving or when not in the same space. An early experimental study by Steve Mann (1996) is one of the pioneers in wearables technology, started by strolling around the street by carrying a computer and wireless equipment that looked heavy which in contrast with current wearables devices, which are light, unnoticeable, and beautiful. Early wearables devices look entirely different but the wearable concept was clearly exhibit by wearing the devices on the user's body to extend the user's mind and body practically (Mann, 1996)

\section{Musculoskeletal Disorder}

Musculoskeletal Disorder are injuries or pain in the human musculoskeletal system including the joints, ligaments, muscles, nerves, tendons and structures that support limbs, neck and back. MSDs can occur due to sudden exertion of lifting heavy objects or they can arise from making the same motions repeatedly repetitive strain, or from repeated exposure to force, vibration, or awkward posture. MSDs can affect many different parts of the body including upper and lower back, neck, shoulders and extremities of arms, legs, feet and hands. Examples of MSDs include carpel tunnel syndrome, back pain, tension neck syndrome and hand-arm vibration syndrome (Kourinka et al.,1987)

\section{Personal Protective Equipment (PPE) in Construction}

Personal Protective Equipment (PPE) is a key to a personal safety at the worker level. Often overlooked and mostly considered as being only a minor player in the overall site safety, 
PPE can be a significant determining factor between accident and safety. Anecdotal evidence suggests that wearing the correct personal protective equipment at all times are important in reducing accidents and should be given higher priority (Laryea, Agyepong, Leiringer, \& Hughes, 2012).

In United Kingdom Regulation 1992, Personal Protective equipment (PPE) is defined as all equipment which intended to be worn or held by a person at work including clothing which protect against the weather and which protects the workers against one or more risks to his health and safety. Personal Protective equipment is equipment worn to minimize exposure to a variety of hazards, where health risk cannot be avoided or processes cannot be improved, the use of appropriate PPE also can be effective measure to protect the health of the workers (Laryea et al., 2012)

The history of PPE at initial development focused on protecting the workers, which then the focus slowly changes to worker comfort, to functionality and performance issues, and finally to style issues. In mid-century, advance in glove styles and compound dipping were complemented by production innovations designed to improve cost and quality. OSHA led to an increased focus on workers product in the mid-1970s. Research that were carried out in the UK results in the workers acknowledge their biggest issues with PPE were to do with comfort and performance. Three-quarters from the respondent said that if the work wear more comfortable, they would be more willing to wear it than is currently the case (Laryea et al., 2012).

Traditionally, work wear has been judged against very basic criteria whether it protect the workers and is it functional enough to let them do their job effectively. While all these factors are obviously important, other issues need just as careful consideration, especially comfort, style and wearability (Taylor, 2011). Protective devices are designed to interpose an effective barrier between harmful object or environment. Personal protective equipment devices should meet the following requirements before it is considered adequate;

- It should provide maximum comfort and minimum weight compatible with the protective efficiency.

- It should ensure adequate production from the hazards to which the workers will be exposed

- It should be durable

- It should impose no restriction on essential movements or works or objections

- It should have maximum attractiveness in appearance

- It should be constructed in accordance with acceptable standards for performance and for the materials.

If the items of protective clothing are uncomfortable and slow down workers, then they are less likely to wear it, which then will increase the probability of accidents and risk that they will suffer injuries (Taylor, 2011). The main requirement of the PPE at Work regulations 1992 is that personal protective equipment is to be supplied and used at work whether there are risks to health and safety that cannot be adequately controlled in other ways. The Regulation also require that PPE:

1. Properly assessed before use to ensure its suitable

2. Maintained and stored properly.

3. Provided with instruction on how to use it safely

4. Used correctly by employees

5. Staff must wear protective clothing as a legal requirement 
Unfortunately, for many workers 'health and safety' is just another in a long line of bureaucratic measures put in place that make it more and more difficult to carry out their day to day duties effectively.

\section{Current Wearables Technology}

Despite the presence of basic responsive clothes already in the market, smart clothing is an emerging research area. Among the products researched are motion detecting pants that are developed by Virginia Tech E-textiles Laboratory, a smart wedding dress (which sense breathing data to illustrate the bride's emotions through Light Emitting Diode (LED) lights and pulsating flowers which were developed by Simon Fraser University (SFU).

A performance animation system was developed using accelerometers sewn into clothing. The accelerometer reading was compared against simultaneous motion capture systems and found a close match (Slyper \& Hodgins, 2008). Similarly, (Kritzler et. al. , 2015) developed a posture classification system using acceleration sensors.

In health and fitness domain, a wearable garment was developed based on physiological signals and body kinematics during exercise. The garments will sense the $\mathrm{pH}$ value of sweat to determine hydration, berating pattern and joint strain during exercise (Ceylo et al.,2009). Similarly, to the wearable garment, the Active T-shirt which using the same concept senses body temperature, heart rate, $\mathrm{CO} 2$ value of the surrounding environment, motion and light level (Senol et. al., 2011).

A heart-rate estimating system together with wearables physiological sensors were developed. The sensors include the temperature sensor, electrocardiogram (ECG) electrodes, sweatiness sensor and respiration sensor. They process the sensory data to estimate the maximum like hood heart rate. Anti-heat stress uniform for construction workers have been developed. It uses moisture-management fabrics that were made from nano-materials were used to produce a T-shirt. With higher one-way transferability and liquid moisture management capacity, the technology improves fabric breathability, speed up sweat evaporation, and help to reduce heat stress. The clothing was developed based on environmental conditions monitored over few months. This clothing cannot monitor the environment conditions real-time to provide feedback (Chan et al., 2012).

\section{Current Status of Musculoskeletal Disorder in Construction Industry.}

A cross-sectional study was conducted on 33 male industrial workers in the industrial company located at Selangor, Malaysia. The study includes field risk assessment, task analysis, and body discomfort survey among respondents. It was discovered that there are 27 main activities that contribute to the MSDs. $94 \%$ of the workers were experiencing neck discomfort and $56 \%$ were experiencing back discomfort. Discomforts at the workers' neck, back, shoulder and arm, and knee and legs amount to $42 \%, 74 \%, 89 \%$ and $29 \%$ of them respectively, as shown in Figure 2.1 (Shamsudin et al. 2017). 


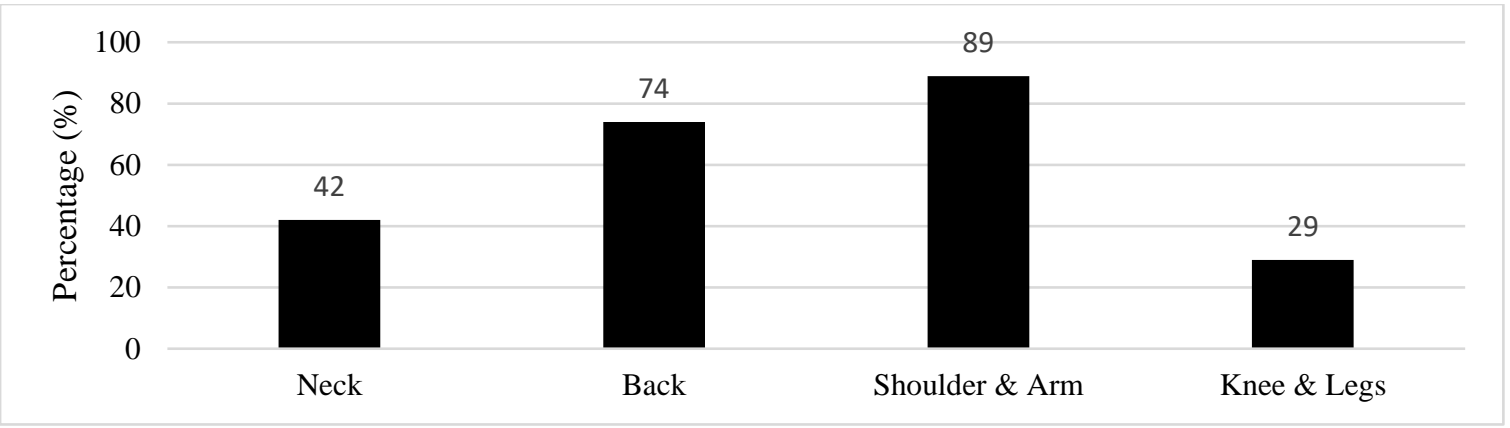

Figure 2.1: Result of survey on discomfort felt at different body regions Source: Shamsudin, Vijayakumar \& Md Daud, 2017

Back discomfort was second highest after shoulder and arms. The use of the back side of the body region for pulling, pushing, and lifting have developed symptoms of discomfort. Back twisting and lateral bending increased the spine muscles and disc injury according to the biomechanical characteristics (Shamsudin et al. 2017). There is an increase in MSD cases even though the employer response rate is still low. On a survey conducted on 30 respondents of industry employers, $87.2 \%$ of them know that MSD is a disorder that affects body movements. Unfortunately, 51.3\% of the respondents did not know MSDs will occur if the workload is higher than physical ability and $46.2 \%$ were not aware of any law in Malaysia that protects workers from MSDs. Depending on the severity level, the condition might be irreversible. Having this wrong information may lead them to ignore the seriousness caused by MSDs on their health and working capability (Nordin et al. 2015). In 2010, a questionnaire was conducted to the randomly selected retired workers that reside in the Netherland that shows that the respondents reported regular or long-lasting complaints of the lower back $(43 \%)$, knees (31\%), and shoulders (31\%) more often. At follow-up questionnaire, $69 \%$ of the respondents with MSDs reported that their complaints resulted partially or completely from their works as a construction worker. About half of the respondents indicated that their complaints worsened because of their work and they experienced limitations in their works due to their MSDs (Boschman et al., 2015).

According to the statistics that were published by the Department of Occupational Safety and Health (DOSH) in 2017 revealed that a total of 126 cases were reported and confirmed by the DOSH officer as Occupational Musculoskeletal Disorder (OMSD). The data statistics revealed that the manufacturing sector and construction sector are the sectors that have to contribute highest OMSD. Until September 2018, DOSH revealed that a total of 85 cases of OMSD were confirmed by the DOSH officer and the state of Selangor was recorded as the state contributing to MSD cases. According to the statistics report about the numbers of accidents by industry in 2015 conducted by SOCSO, 2,900 cases were reported in the construction industry. For the number of occupational diseases by causing agent reported in the year 2015 by SOCSO (SOCSO, 2015), 708 cases were reported in OMSDs. Recent studies and statistics showed that the rates of musculoskeletal injuries and disorders among workers in the construction trades are much higher when compared to those working in other industries. In addition, data about the occupational disease by private workers from the National Worker's Social Security Organization in Malaysia from 2002 until 2006 shows that from overall incidence rate, were 2.8 cases in every 100,000 workers experiencing MSDs. Most of them often suffer pain, numbness, tingling, and swelling around their bodies. These worst MSD pains and injuries may be caused by manual handling of heavy material, which 
including lifting, lowering, carrying, pulling, pushing, and also forced to work overtime in long hours such as 12 hours-shifts and six days a week (Santos et. al 2014).

The current statistics that were published through SOCSO online journal recorded an increasing amount of MSD cases throughout the year of 2014 until 2017 as seen in Figure 2.2. A total of 675 cases of MSDs were reported in 2017 where 416 of them were males and 259 of them were females. The higher numbers of cases among men are because they dominated the construction industry. In the year 2015 , a total of 708 cases were reported and recorded by the SOCSO where 451 of the patients were males and 257 of them were females. This increasing pattern in MSDs every year is very disturbing. A total of 1,006 cases of MSDs was recorded in the year 2016, which compromises 683 males and 323 females. Significant increase of 298 cases between 2015 and 2016 is alarming. In the year 2017, the MSDs cases recorded are at 1,354 cases where 918 of them were males and 436 of them were females. An average of 170 cases were reported each year and the trend seems to be increasing (SOCSO, 2017).

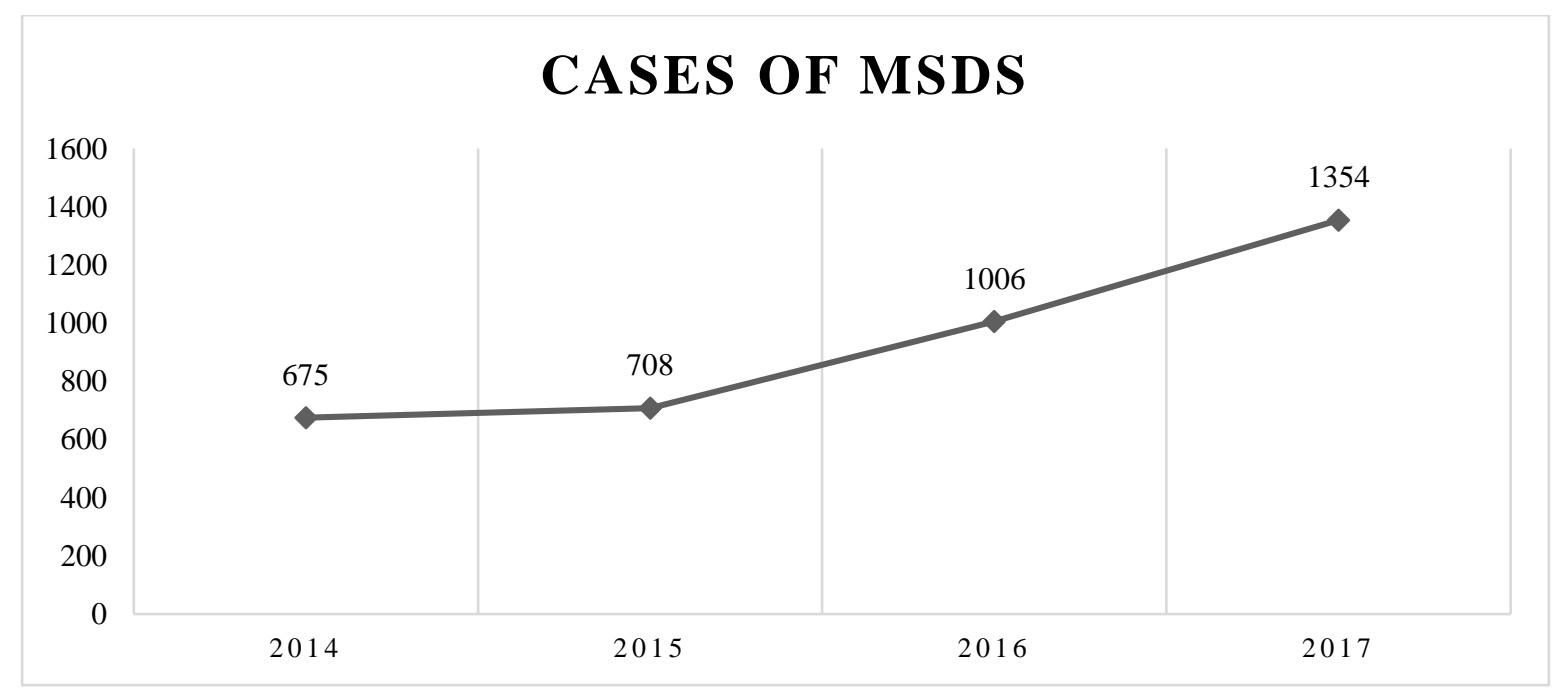

Figure 2.2: Number of Cases for MSDs for the year 2014 until 2017 Source: (SOCSO, 2017)

The MSDs occur when the wrong posture and lack of tools that makes the posture even worse even during works. Construction workers from different trade or construction activities belong to the high-risk groups for MSD. A number of trade or construction activities impact on construction ergonomics such as plastering, laying floor screeding, pipe laying, pipe fitting, painting, joinery, glazing, bricklaying, concreting, roofing, and rebar works (Smallwood, 2000). Most work-related MSDs are cumulative disorders, which result from repeated exposure to high or low-intensity loads over a long period of time. MSDs cause harm and suffering to the workers and have an enormous negative impact on society. At the workplace level, the disorder results in increased production cost due to reduced human capacity and disturbance to productions. The costs to society are increased due to the need for treatment and rehabilitation, in addition to the compensation costs paid through social insurances. Different construction trades are exposed to various kinds of physical workload, involving different parts of the body (Holmstrom et al. 1995). The construction industry continues to be one of the highest risk industries contributing to the development of WMSDs. Different construction trade workers are exposed to risk factors depending on their job and task. Table 2.1 stipulated 
the several trades involved in construction projects related to the MSDs symptoms (Suzila et.al 2017).

Table 2.1: Trades Involved in Construction Industry and Their Relations to WMSDs.

\begin{tabular}{|c|c|c|c|c|c|}
\hline Trade & $\begin{array}{l}\text { Nature of } \\
\text { Work }\end{array}$ & $\begin{array}{l}\text { Problematic } \\
\text { Work- } \\
\text { Related } \\
\text { Activities }\end{array}$ & Activities & $\begin{array}{l}\text { Risk } \\
\text { Factors }\end{array}$ & MSDs \\
\hline $\begin{array}{l}\text { Plasterer } \\
\text { (Rwamamara, } \\
\text { 2005) }\end{array}$ & $\begin{array}{l}\text { Plastering was } \\
\text { normally } \\
\text { commenced } \\
\text { at the upper } \\
\text { level and } \\
\text { continued } \\
\text { downwards. }\end{array}$ & $\begin{array}{l}\text { Bending and } \\
\text { twisting of } \\
\text { the body, } \\
\text { lifting heavy } \\
\text { materials }\end{array}$ & $\begin{array}{l}\text { Working above } \\
\text { shoulder height } \\
\text { and reaching } \\
\text { overhead, } \\
\text { working } \\
\text { overhead, } \\
\text { working below } \\
\text { knee level, } \\
\text { working when } \\
\text { kneeling }\end{array}$ & $\begin{array}{l}\text { Repetition, } \\
\text { force }\end{array}$ & $\begin{array}{l}\text { Shoulder } \\
\text { disorder, } \\
\text { Upper } \\
\text { arm } \\
\text { disorder, } \\
\text { Neck } \\
\text { Disorder }\end{array}$ \\
\hline $\begin{array}{l}\text { Painter } \\
\text { (Rwamamara, } \\
\text { 2005) }\end{array}$ & $\begin{array}{l}\text { A painter is a } \\
\text { trade person } \\
\text { who } \\
\text { responsible } \\
\text { for the } \\
\text { decorative } \\
\text { and protective } \\
\text { coloured } \\
\text { coating to } \\
\text { building } \\
\text { surfaces. The } \\
\text { painting was } \\
\text { done while } \\
\text { standing at } \\
\text { ground or } \\
\text { floor level as } \\
\text { well as } \\
\text { elevated } \\
\text { positions. }\end{array}$ & $\begin{array}{l}\text { Bending and } \\
\text { twisting of } \\
\text { the body. }\end{array}$ & $\begin{array}{l}\text { Working below } \\
\text { knee level, } \\
\text { working above } \\
\text { shoulder height, } \\
\text { reaching } \\
\text { overhead. }\end{array}$ & $\begin{array}{l}\text { Awkward } \\
\text { posture, } \\
\text { Force. }\end{array}$ & $\begin{array}{l}\text { Lower } \\
\text { back } \\
\text { disorder, } \\
\text { Shoulder } \\
\text { disorder, } \\
\text { Upper } \\
\text { arm } \\
\text { disorder. }\end{array}$ \\
\hline $\begin{array}{l}\text { Concreter } \\
\text { (Rwamamara, } \\
\text { 2005) }\end{array}$ & $\begin{array}{l}\text { Concreter is } \\
\text { labour that } \\
\text { works with } \\
\text { concrete } \\
\text { works such as } \\
\text { floor } \\
\text { concreting. }\end{array}$ & $\begin{array}{l}\text { Bend their } \\
\text { back and } \\
\text { twisting the } \\
\text { right side } \\
\text { when } \\
\text { concreting } \\
\text { floor in an } \\
\text { awkward } \\
\text { position }\end{array}$ & $\begin{array}{l}\text { Straight leg, } \\
\text { Work in a static } \\
\text { position and } \\
\text { moving/twisting }\end{array}$ & $\begin{array}{l}\text { Awkward } \\
\text { posture }\end{array}$ & $\begin{array}{l}\text { Back pain, } \\
\text { shoulder, } \\
\text { wrist } \\
\text { region, } \\
\text { and neck. }\end{array}$ \\
\hline
\end{tabular}




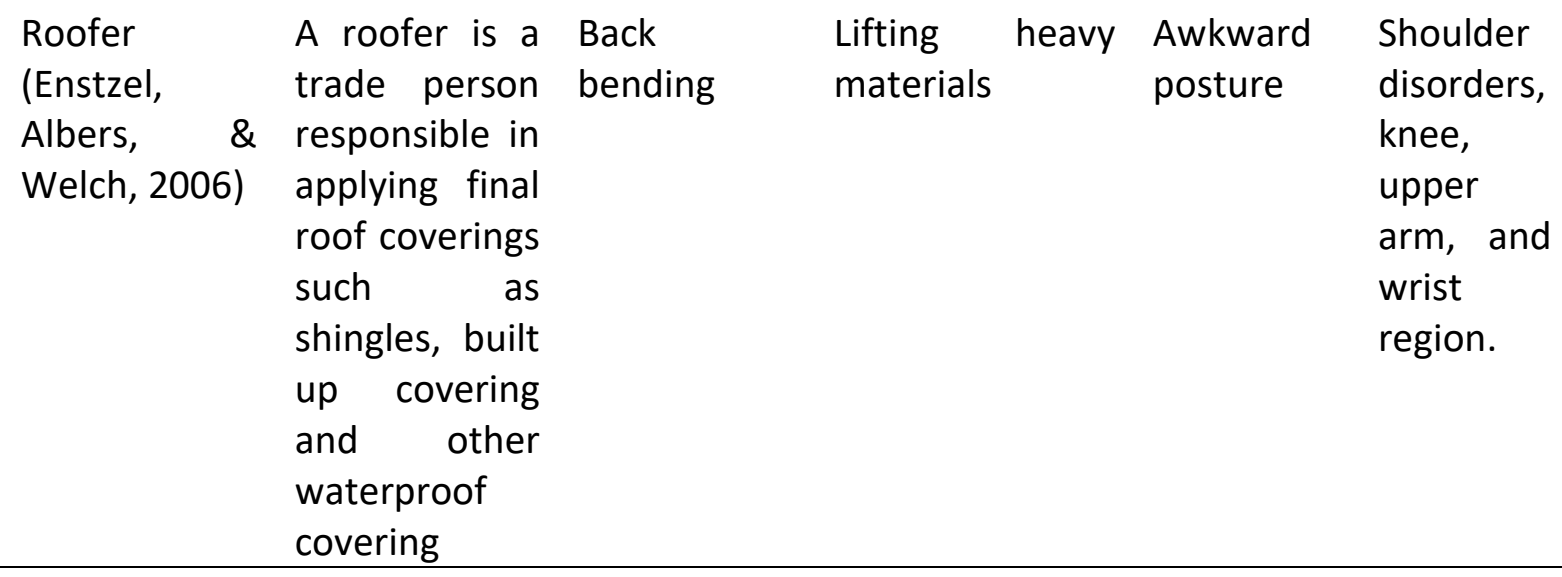

Source: (Nor Suzila, Mohd Kamar, Abdul Aziz, Abdullah, \& Mt Akhir, 2017)

According to the survey that was conducted to 37 construction workers in Malaysia to acquired their opinions regarding MSD found that there are many causes of major pain experienced by the workers due to construction works. Table 2.2 presented the causes that were identified. Manipulation of heavy load, awkward working posture, and high force exertion were reported as main contributors to major pain, while the causes related to static loading and repetitive work are rarely complained (Halim et al. 2012).

Table 2.2: Causes of major pain or discomfort occur during doing the works

\begin{tabular}{ll}
\hline Causes & No. of Complaint \\
\hline Manipulation of heavy load & 15 \\
High force exertion & 7 \\
Awkward working posture & 9 \\
Static loading & 4 \\
Repetitive work & 1 \\
\hline
\end{tabular}

Source: (Halim et al. 2012)

\section{Implementation on Construction Wearables Technology}

As opposed to the other industry, the application of wearable technology in the construction industry is at the early stages. In fact, there are very few cases of applications that were documented and recorded in the construction industry (Cheng et al., 2012). One of the very few implementations was the evaluation of a method for testing proximity detection and alert systems to promote safety on construction site. Also, a hands-free system was employed to monitor workers and increase their situational awareness by continuously collecting data on the jobsite, detecting environment conditions, and the proximity of workers to danger zones (Friedman, 2015). The lack of wide-spread implementation is due, in part, to a lack of reliable data supporting their potential benefits.

Although, the construction industry may be slow in adopting robotics and automation tools, and other technologies that can increase efficiency, wearable technologies could uncover possibilities for improvements in the construction industry. Thus, there is a great potential for implementation of wearable technology for safety monitoring in the construction industry (MacDonald et al., 2009). 


\section{Development of Idea}

The development of innovation idea started with finding the issues and problems on the current situations of the health and safety in the construction and manufacturing industry by literature review. Manufacturing and construction of IBS are chosen as IBS involve with the modern construction technology which aligned with the IBS Roadmap stated by the government towards the Industrial Revolution (I.R 4.0). However, despite such technologies is emerging in Malaysia the process of making and installing of the precast components are still using heavy workers to execute the works. Therefore, Occupational Diseases among the workers have increasing and it affects the workers in daily life for a long-time of period.

Prior to solve the issues and problems, research questions and objectives were made as a guidance to the findings of the innovation idea. Thus, critical reviews on the existed method and technology in wearables related has been done in order to obtain the innovation concept and idea. The innovations idea approaches the problems of having to bear a high cost of technology to the industry players if they were to opted to the wearables technology in the market instead of the workers. For examples, the cost of the Exoskeleton Suit is expected to price at 1.5 million USD (RM 4,186,500) for a single suit. Thus, the idea of creating wearables that is affordable enough and can cater to the safety and health of the workers are developed. The evolution of wearables technology throughout the years may provide design characteristics with concept and idea in realizing the wearable technology into the on-site manufacturing and construction industry. Also, the innovation that are developed aims to improve the productivity of the workers and increase the speed of the construction industry and reducing the risk of injuries in term of MSDs among the workers.

Therefore, the new concept of innovation idea is made to ensure a safe environment to the construction and manufacturing site and the workers thus enhancing the quality of life of the workers. The design of the innovation idea was inspired by the skeletal suit (exoskeleton) that were developed and the standard safety jacket. The application of the innovation idea shall ensure that the injuries and discomfort to the workers are reduced, cost effective, enhancing the safe environment, and sustainable to the environment.

\section{Materials and Method}

\section{Research Methodology and Data Collection}

For the purpose of this research and in order to achieve the objectives, primary and secondary data will be collected and used. The secondary data will contribute toward the formation of background information, needed by both the researcher in order to build constructively the project and the reader to comprehend more thoroughly the survey outcome. This research will adopt mixed method approach and under this section, the research instrument that have been selected for this research will be discussed in greater detail, with the appropriateness of use for this study reiterated.

\section{Literature Review}

Secondary data was collected through the literature review and desk study. Articles on MSDs among the industrial workers in Malaysia were reviewed. Problem statements were developed during the process of literature review. The articles reviewed were also on the challenges faced by the implementation of robotics and technology in the construction industry. The article on works that have been contributing to a higher case of MSDs was also reviewed to identify nature and how the disease can happen. This method is done to get a 
better and clearer picture of the aims, objectives, and problems for better improvements in the innovation that will be done.

Desk-study was also done to collect data on a more detailed definition of MSDs and the activity that have the highest contribution to the MSDs. Desk study is done to identify the evolution of the safety jacket and skeletal mechanism up until today. It is to compare and highlight the strength and weakness of each product that has been developed. Desk-study provides an initial understanding of the situations and enable identification of potential risks and inform the details of subsequent investigations (Jafri et al. 2012).

\section{Personal Observations}

The collection of data was done through observation. Observation was made for 30 days through different construction site and different IBS precast component factories. The observation was made on IBS precast panel manufacturing workers to understand more about their scope of works. There are a few things that was recorded, which was the way the workers work and whether there is a direct link between MSD and the manufacturing of precast components. The data collected was documented and recorded physically by using pen and papers and virtually by using the software. Observation was made to physiotherapy ward to better understand how the mechanism of the human body works and to assist in improving the innovation of the products.

\section{Interview}

There are four types of respondent group that will be interviewed for the collection of data. The first respondent is the IBS precast components manufacturer, the second one is the physiotherapy specialist, the third one is the industrial workers and the last one is the officer from DOSH Malaysia. The reasons why those respondents are selected is because all of them are involved directly or indirectly with the process of developing innovative products. The physiotherapy specialist is selected as one of the respondents because of their opinion and importance in producing the mechanism that will be done to help in preventing the MSDs. Their opinions and knowledge in physiotherapy is also important in identifying the first objectives which are to identify long-term problems that will occur when MSD is not treated. The reasons why the IBS manufacturer, an officer of DOSH and industrial workers selected is to know their opinions on the innovations and to take into considerations other improvements that were suggested by them for the product innovation. There are a few questions that were asked, which are the level of knowledge or understanding in the MSD that occur among the industrial workers. Their opinions on the innovations were asked for further or future improvements that can be taken into consideration. There are few tools or devices that were used to record the data including video recorder, camera and audio recorder. The interviews were done in a detail manner so that the data collected is more accurate.

\section{Questionnaire Survey}

A questionnaire was developed and distributed to the construction firms of contractors, specialist sub-contractors, developers and consultants to establish the extent of usage and related value of the proposed innovations. These companies were asked to provide input regarding industry perception, suggested improvements and marketability of the innovation products. The type of chosen is a closed questionnaire, is divided into five main section, that is, demographic information, MSDs issues among workers, details of the proposed innovation 
idea, marketability of the proposed innovation idea and comments and recommendations. Details of the questionnaire are further described in the paper. A copy of the questionnaire for this research survey is included in Appendix 1 of the paper.

\section{Simulation}

In this research paper, simulation of the proposed innovation will be done using suitable software such as Sketch Up and 3D Max. The purpose of simulation method was selected was to give better understanding to others people on the design, function and how the system works. The simulation done also will give the researches virtual hand-on before the proposed innovation is executed physically. This will give chances to the researcher to improve the design and function virtually without having to bear a high cost.

\section{Data Analysis}

The statistical tests selected for use in this research include cross tabulation analysis. The results that have been collected by the questionnaire were tabulated into graphic to give better understanding for the outcome. The results of the statistical analysis produced for the questionnaire were then integrated with the qualitative analysis of the interview, to facilitate the formulation of possible conclusions and recommendations for the research.

\section{Material for the proposed innovation}

Table 3.1 shows the material that will be used for each component for the proposed innovation. Textrodes and fabric mesh are used for the safety jacket to implement the smart element in the proposed element. Textrodes fabric is one of the smart fabrics where it incorporated the sensor that can detect the heartbeat of the wearer and durable enough to be wash in the cleaning chemical. Soft nylon mesh is used as the material for the backpack straps to reduce rubs, itchiness and irritation during active. This material is taken into consideration after knowing that there are some of the wearer might have sensitive skins.

For the housing of the cable winding and plastic strip, polycarbonate is used due to its durableness and lightweight. The housing and plastic strip will be printed using the 3D printer machine to get the exact measurement and design to fit the Ratchet Mechanism. For the cable tie, Polyethylene braid-style cables are used as it has high extension up to $34 \mathrm{~kg}$ and has low deformability. Velcro tapes that are used for the Velcro strap are used as it has high strength and can support the lower back better than other material. It also has a low maintenance and great strength. 
Table 3.1: Material for each component for the proposed innovation

\begin{tabular}{|c|c|c|c|}
\hline NO. & COMPONENTS & MATERIAL & ADVANTAGES \\
\hline 1. & Safety Jacket & $\begin{array}{l}\text { Textrodes, } \\
\text { mesh }\end{array}$ & $\begin{array}{l}\text {-move sweat from body } \\
\text {-avoid saturation and accelerate drying } \\
\text {-to achieve cooling effect } \\
\text {-can detect heart beat } \\
\text { (Quandt et al., 2017) }\end{array}$ \\
\hline 2. & Backpack strap & Soft nylon mesh & $\begin{array}{l}\text {-reducing rubs during active use } \\
\text {-durable } \\
\text {-reduce itchiness and irritation }\end{array}$ \\
\hline 3. & $\begin{array}{l}\text { Housing for } \\
\text { cable winding }\end{array}$ & Polycarbonate & $\begin{array}{l}\text {-strong } \\
\text {-easily work with } \\
\text {-light } \\
\text {-durable } \\
\text { (Zhang \& Arakelian, 2019) }\end{array}$ \\
\hline 4. & Cable tie & $\begin{array}{l}\text { Polyethylene } \\
\text { style cables }\end{array}$ & $\begin{array}{l}\text { - high strength of extension up to } 34 \mathrm{~kg} \\
\text {-low deformability } \\
\text { (Zhang \& Arakelian, 2019) }\end{array}$ \\
\hline 5. & Velcro strap & VELCRO tapes & $\begin{array}{l}\text {-great strength } \\
\text {-low maintenance } \\
\text {-ease of use } \\
\text { (Ruben Castaneda, 2017) }\end{array}$ \\
\hline 6. & Plastic strip & Polycarbonate & $\begin{array}{l}\text {-strong } \\
\text {-easily work with } \\
\text {-light } \\
\text {-durable } \\
\text { (De Busk, Babski-Reeves, \& Chander, } \\
2017 \text { ) }\end{array}$ \\
\hline
\end{tabular}

\section{Summary}

In summary, the innovation idea was created due to the current issues and problems identified on the safety and health among the construction and manufacturing industry workers based on the literature review that have been done. A comparative analysis is made where comparisons between existing machineries and robot with the innovation idea as the results of findings. A solution for the problems is made by referring to the data that has been analyzed in order to improve the innovation idea.

The implementation of wearable technology product to the construction industry has the potential to improve the industry in terms of productivity, safety and quality. Positive factors can facilitate the transfer of wearables technology to the construction works processes whilst the negative factors tend to create barriers to adoption. this introduction chapter brings together related issues pertaining to construction wearables technology in establishing the research questions, objectives and research problems in context of the research. It also provides the flow of progression in terms of the research framework, contributions and a brief description of the research methodology. This forms an overview of the basis of the research work which will later be discussed comprehensively in proceeding chapters. 


\section{Result and Discussion \\ Results of Proposal}

The findings which comes from the desk study and literature review conducted, the first and second objectives are answered which is to propose a wearable gear to ease the work of the workers for the installation and manufacturing of the precast concrete component related to the IBS system. This innovation also aims to increase productivity and reduce the risk of neck and back discomfort to the manufacturing and construction workers.

There are many innovative products of exoskeleton, however, their functions are limited to ease the process of lifting heavy objects and limited to the indoor environment. Skeletal safety jacket is specifically proposed to cater of the problems of incorporating technology to safety and health without the industry player and workers having to bear a high cost by purchasing an exoskeleton that have limited functions.

\section{Assembly of Product}

This safety jacket has a standard dimension of typical construction safety jacket that will suit an average person's head, fitted with an adjustable strap at the hip to suit the person's body size. The safety and comfort factors need to be taken into account so that the wearer is able to wear it for a period of time without agitation.

The assembly of passive skeleton safety jacket starts with stitching together Tektron fabrics to form the standard dimension of safety jacket. The inner layer of the jacket will compromise of fabric mesh. Then, the backpack straps will be stitched to the jacket together with the reflective strips. Velcro Strap with GPS embedded in it will then be stitched together to the jacket. Cable winding and locking mechanism will be install at the shoulder of the safety jacket. Heartbeat sensor will then be installed in the pocket with zips that can be assessed easily near the backpack strip. Following this, the plastic strip with soft pad will be installed at the back of the safety jacket. The summary of assembly of passive skeleton safety jacket is shown in Figure 4.1.

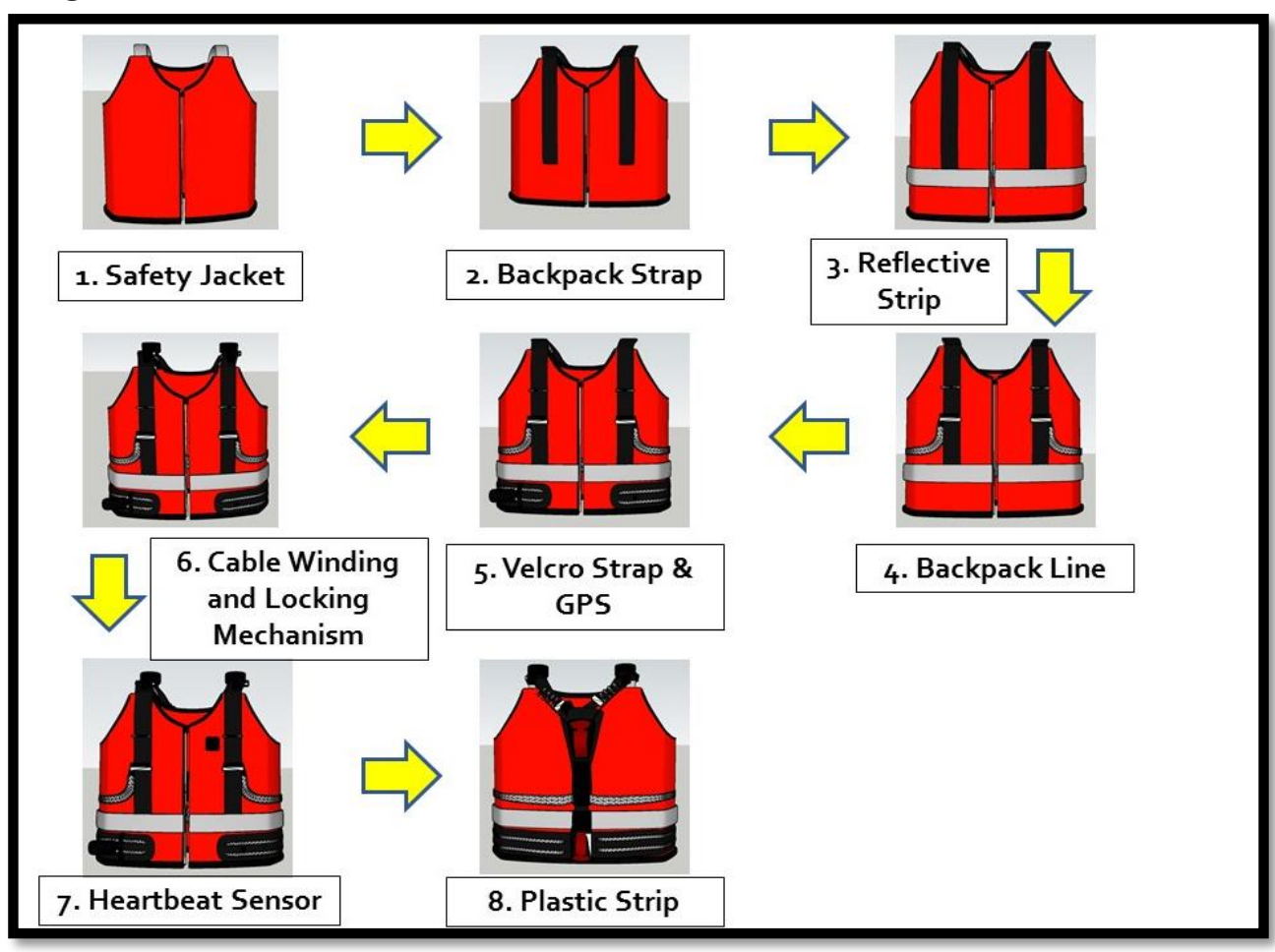

Figure 4.1: The assembly of passive skeleton safety jacket 


\section{Feature of Passive Skeleton Safety Jacket}

The passive skeleton safety jacket shall contain features to perform tasks efficiently and accurately, whereas the safety and health are the main element for the jacket. Therefore, some features contained in the passive skeleton safety jacket can enhanced the functionality of the product to performs under extreme environment while maintaining a safe and sustainable environment in the processes of work.

\section{Safety Jacket}

The dimension of the safety jacket follows the standard requirement of the existing safety jacket. The size of the jacket can be adjusted using the Velcro strap at the waist for better support. Velcro strap are one of the simple lumbar support devices. This feature is useful for improving function and reducing pain among those suffering from subacute back pain, which is sudden and short in duration but not long-lasting enough to be chronic. The Velcro strap will provide enough compression and support for the lower back and lessen the pressure on lower back disc, muscles and spine. The proposed skeletal safety jacket also equipped with a reflective strip at the chest and at the back of the jacket so that the wearer can be seen in the dark.

\section{Cable Winding and Locking Mechanism}

The feature of the proposed skeletal safety jacket design is that it consists of a light plastic frame and a cable system mounted via joints on the frame. Polyethylene braid-style cables are used which have a high strength of extension up to $34 \mathrm{~kg}$ and low deformability. With the help of cable winding and locking mechanism, during the transporting phase of load carrying, the gravity of the load can be compensated by the cables and redistributed on the shoulder and thigh. Hence, the pressure of muscles on arm can be relieved.

A Ratchet mechanism is used as locking mechanism. While carrying loads, wearer can engage the locking mechanism by pressing the activation button installed on their thumb, then the pawl is pressed and enter the gap between two teeth of the ratchet then the spool is stopped from moving and the generated cable tension can be used for compensating the gravity of load. In contrast, when the user is not carrying load and activation button is released, the pawl will lift up and the spool can freely rotate. Figure 4.6 shows the mechanical components of the Ratchet mechanism. Figure 4.2 shows the position of the locking mechanism.

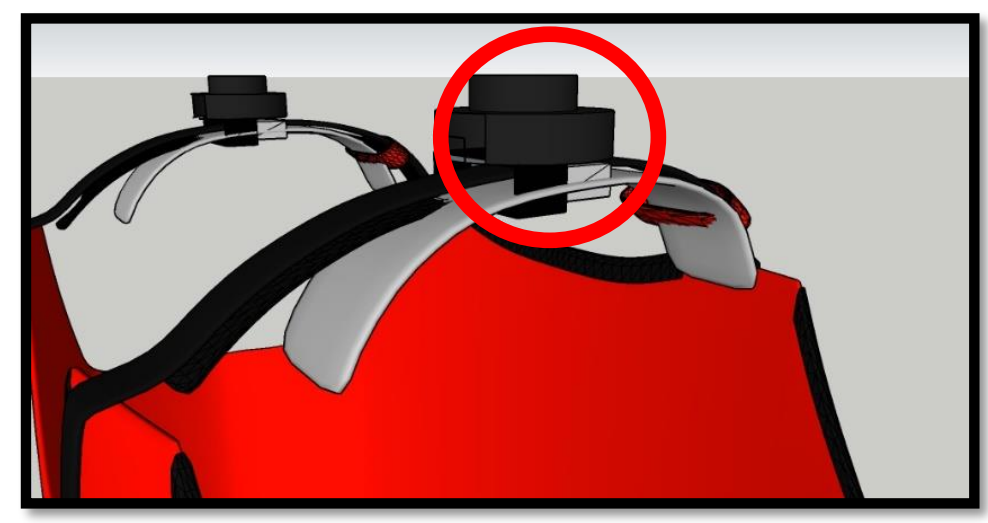

Figure 4.2: The design and position of the cable winding at the passive skeletal safety jacket. 


\section{Backpack Straps}

The feature of the backpack straps is added to the safety jacket so that the wearer can have sense of safety and have firm grip of the skeletal system. The backpack straps can be tightened and loosen according to the wearer preference. Figure 4.3 show the design of the backpack straps at the skeletal safety jacket.

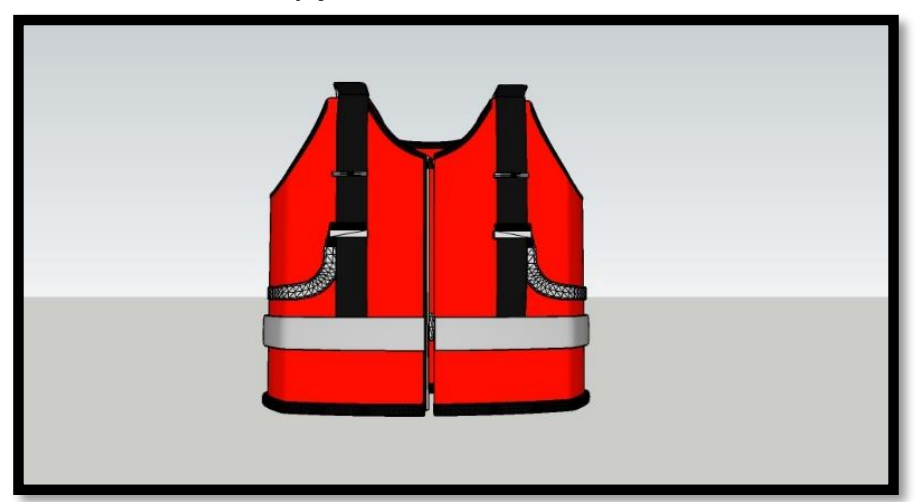

Figure 4.3: The position of backpack strap in passive skeletal safety jacket

\section{Heartbeat Sensor}

This skeletal safety jacket also will be equipped with heartbeat sensor so that the administration can detect the heart pulse of the wearer and can record the data whether they are exhausted or not. There are 2 types of sensor that will be used in this innovation jacket. First sensor which is the pulse sensor will be placed at the fingertip of the cable winding and locking mechanism in Figure 4.9. Figure 4.10 shows the types of pulse sensor used. Figure 4.11 shows the block diagram on how the pulse sensor works. Arduino Mega will be powered up and will start communicating with sensors attached to it. When all necessary data from the pulse rate are received, the whole data will be fed into a Wi-Fi shield module named ESP8266 whose primary job is to configure itself with the router attached and get a dynamic IP. Once IP is generated, the whole data will be wirelessly transmitted to that particular IP (Abro et al., 2019).

Second, the heartbeat sensor will be placed at the neck of the safety jacket. This heartbeat sensor actually is a smart fabric that can detect the heartbeat of the wearer. Smart fabric was developed by the researches at Swiss Federal Laboratories for Materials Science and Technology, Dubendorf which then published an article thru the Journal of The Royal Society Interface. The smart clothing compromises of two different materials (both polymers) which are melt-spun into a fiber optic thread. One polymer is a coating and the inside of the thread is different fiber optic polymer that can transmit light over long distances. The thread is durable enough to stand up to the strict washing regimens is ready to be fashioned into sensor. Polymer optical fibers (POF) are melt-spun continuously and characterized optically and mechanically before being embroidered. POF are well suited for integration into technical textiles. The POF sensing techniques used for the system are based on photoplethysmography for the heart rate sensor (Quandt et al., 2017). The sensor for measuring the physiological parameters are integrated into garments. Figure 4.12 shows the position of smart fabric that can detect heartbeat sensor in passive skeleton safety jacket. 


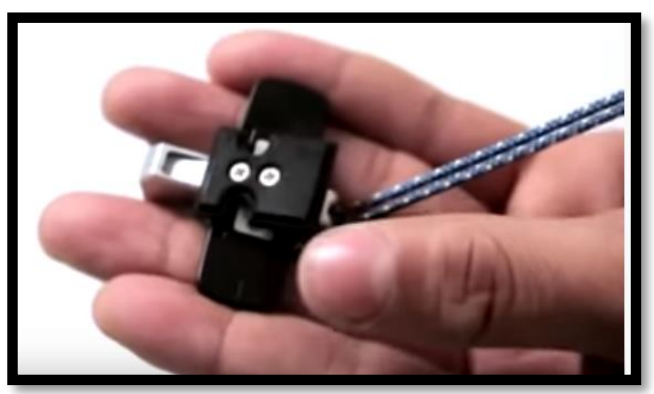

Figure 4.9: The position of the pulse sensor that will be installed

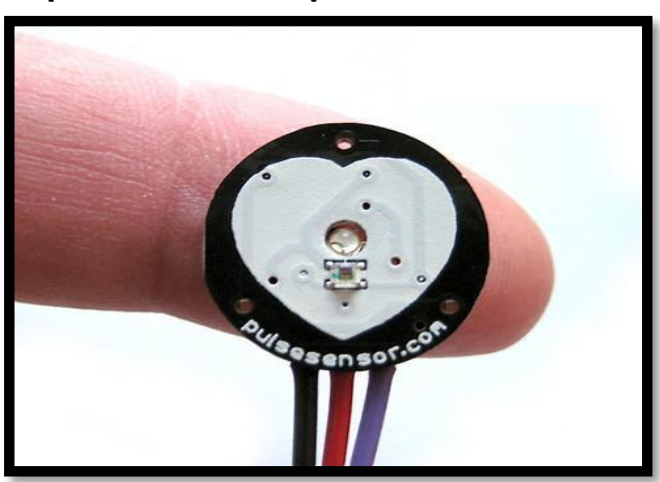

Figure 4.10: Types of pulse sensor used

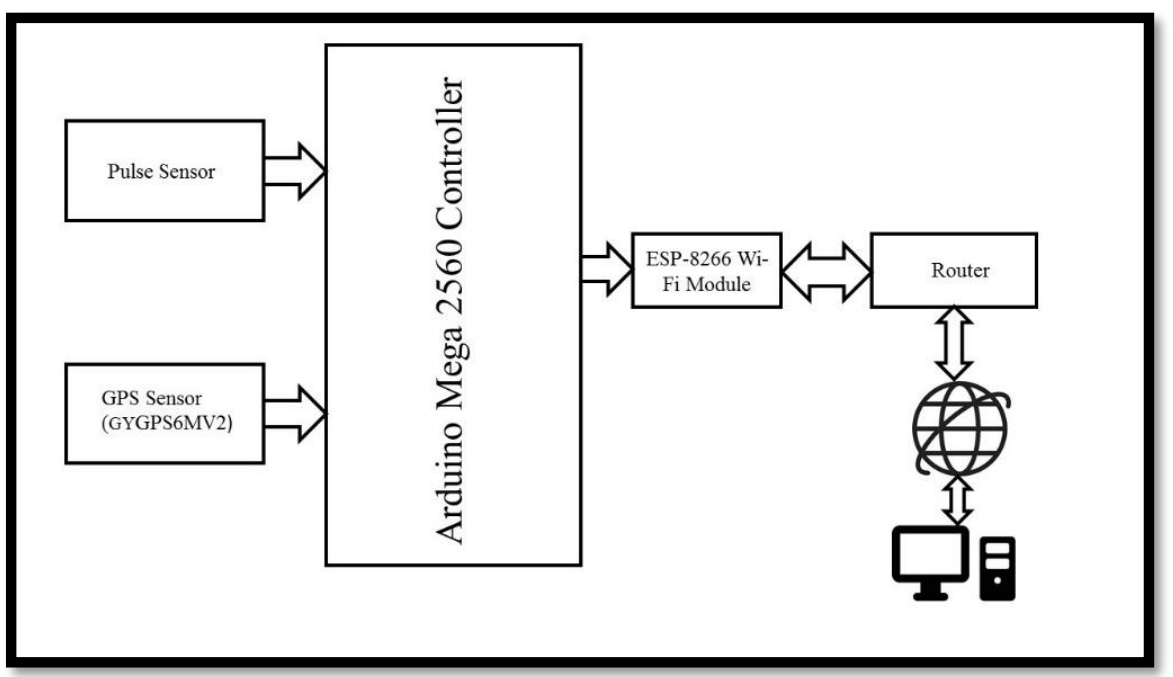

Figure 4.11: Proposed block diagram for the installation of pulse sensor

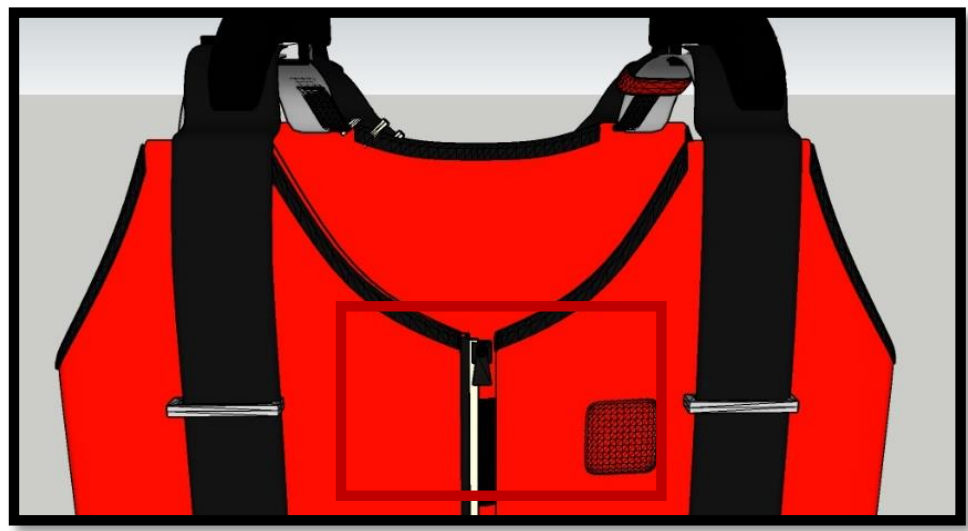

Figure 4.12: The position of heartbeat sensor fiber textiles in passive skeletal safety jacket 


\section{Global Positioning System (GPS)}

GPS are added so that the administration can detect the exact position of the wearer in a large construction site. This feature also helps in detecting hazard that happened to the workers. This feature is featured after consideration of a large construction site where the monitoring camera cannot capture every worker. To shorten the time where medical assistance when the workers are injured, this feature are added. Figure 4.13 shows the position of GPS in Skeletal Safety Jacket which are embedded in the jacket. Figure 4.14 shows the proposed block diagram for the installation of GPS. The types of GPS that will be used is GYGPS6MV (refer Figure 4.15).

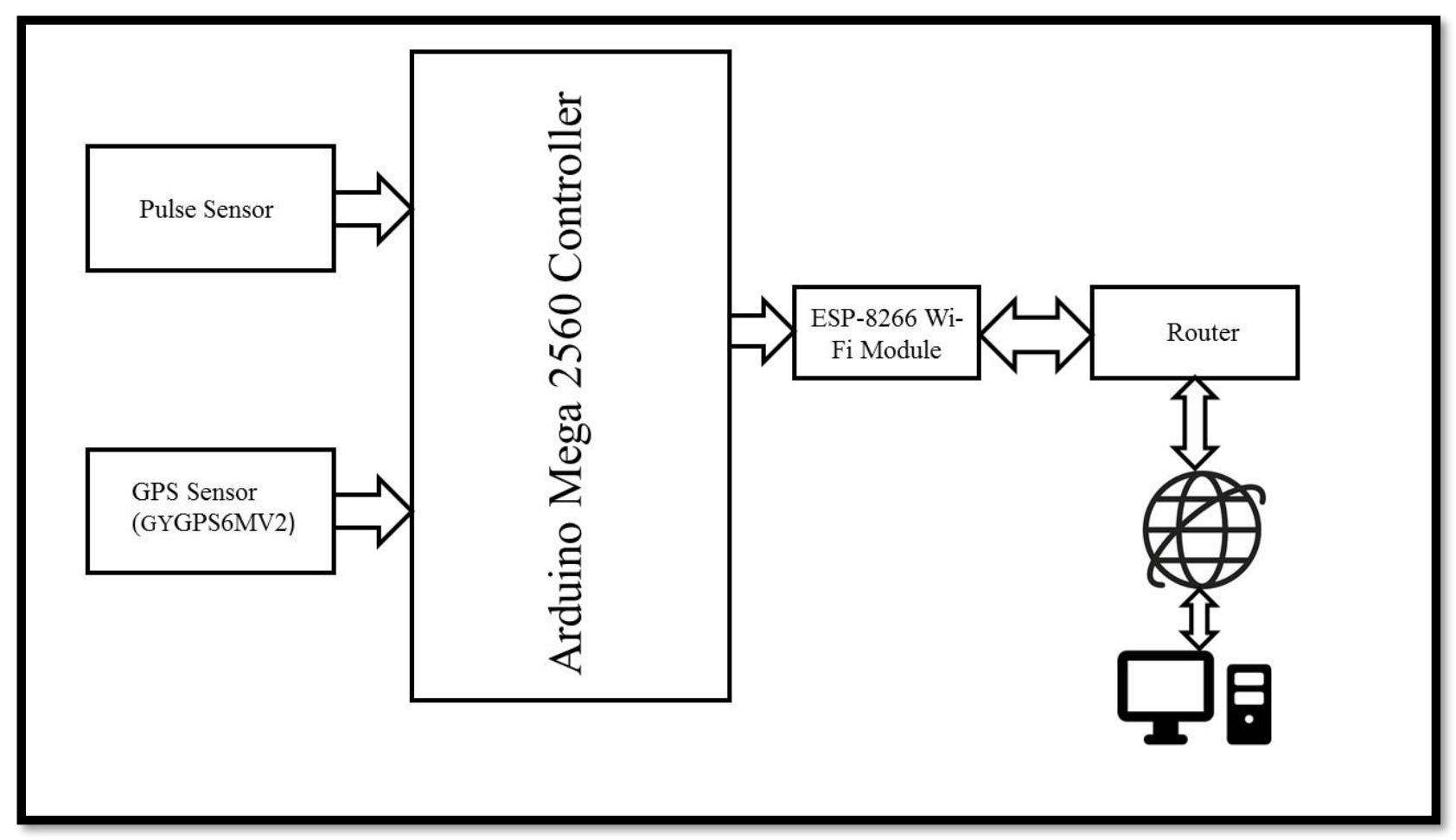

Figure 4.14: Block diagram for the proposed process

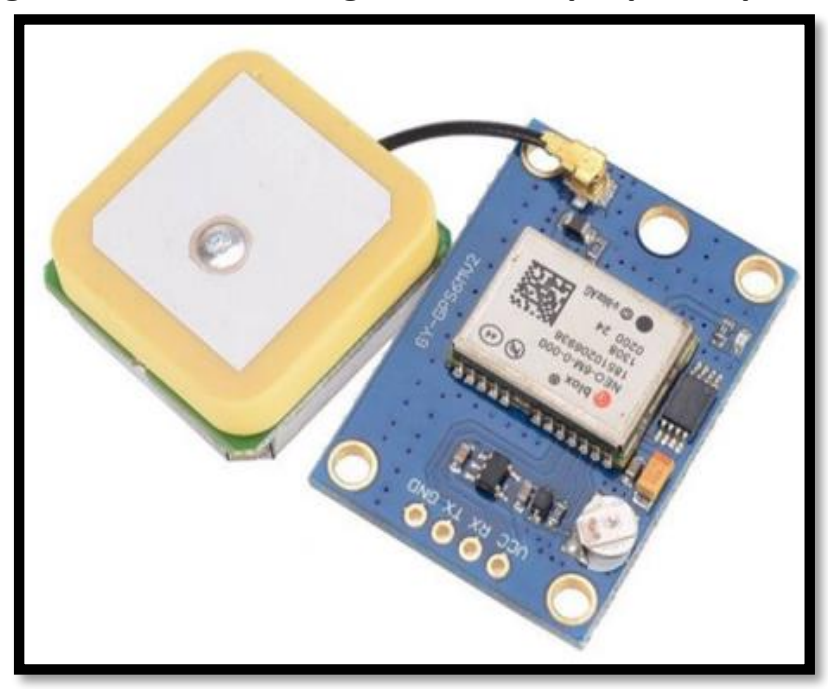

Figure 4.15: GYGPS6MV GPS 


\section{Performance Analysis (Data Comparison)}

Table 4.1 shows the comparison of products that is already available in the market with passive skeleton safety jacket. Comparison will be done with the existing safety jacket and existing passive exoskeleton. This is done to show the performance and summarize the features and characteristics that the products offer and differ with the other. It can be seen that each product exists for a different purpose. Existing safety jacket is a widely used and common safety garment for any industrial workers and FLx Ergoskeleton are one of the existing passive exoskeleton products that is available in the market.

Table 4.1: Comparison of Existing Product and Passive Skeleton Safety Jacket

\begin{tabular}{|c|c|c|c|}
\hline Item & Safety Jacket & FLx Ergoskeleton & $\begin{array}{l}\text { Passive Skeleton } \\
\text { Safety Jacket }\end{array}$ \\
\hline Purpose & $\begin{array}{lr}\text { Safety } & \text { gear } \\
\text { necessary } & \text { to keep } \\
\text { personnel visible to } \\
\text { other } & \text { people } \\
\text { especially } & \text { when } \\
\text { working } & \end{array}$ & $\begin{array}{l}\text { To assist or augment the } \\
\text { user physically but } \\
\text { instead focuses } \\
\text { exclusively on keeping } \\
\text { the user safe }\end{array}$ & $\begin{array}{l}\text { To help in reducing } \\
\text { serious hazard on } \\
\text { body discomfort and } \\
\text { keeping the user safe } \\
\text { in the procurement } \\
\text { area. }\end{array}$ \\
\hline Material & polyster & Rugged plastics & $\begin{array}{l}\text { Textrode and } \\
\text { polycarbonate }\end{array}$ \\
\hline Cost & RM10 RM15 & $€ 585.60$ (RM 3,200) & \\
\hline Weight & $181 \mathrm{~g}$ & $1.12 \mathrm{Kg}$ & $1.10 \mathrm{Kg}$ \\
\hline Feature & Reflective strip & $\begin{array}{l}1 . \quad \text { Height } \\
\text { adjustment }\end{array}$ & $\begin{array}{ll}\text { 1. } & \text { Backpack } \\
\text { strap } & \end{array}$ \\
\hline & & $\begin{array}{l}2 . \quad \text { Flexibility } \\
\text { adjustment }\end{array}$ & $\begin{array}{l}2 . \quad \text { Cable } \\
\text { winding and locking } \\
\text { mechanism }\end{array}$ \\
\hline & & & 3. Plastic strip \\
\hline & & & GPS \\
\hline & & & $\begin{array}{l}\text { 5. Heartbeat } \\
\text { sensor }\end{array}$ \\
\hline Safety Level & MEDIUM & LOW & $\mathrm{HIGH}$ \\
\hline Health Level & LOW & $\mathrm{HIGH}$ & $\mathrm{HIGH}$ \\
\hline $\begin{array}{l}\text { Aid in body } \\
\text { discomfort }\end{array}$ & $x$ & Back support & $\begin{array}{l}\text { Back support } \\
\text { Arm support }\end{array}$ \\
\hline
\end{tabular}

\section{Summary}

In summary, this proposed innovation intends to assist the construction and manufacturing workers when they are carrying heavy loads. The feature of the skeletal safety jacket design is that it consists of a light frame and a cable system mounted at the frame of the shoulder. Polyethylene braid-style cables are used which have the high strength of extension up to $34 \mathrm{~kg}$ and low deformability (Zhang \& Arakelian, 2019). With the help of the cable winding and locking mechanism, during the transporting phase of load carrying, the gravity of the load can be compensated by cables and redistributed on the shoulder and thigh. Hence the pressure of muscles on arm can be relieved. In order to have the optimal assistive effect, the position of anchor and cable attachment points have been optimized. For safety of the user, silicon material is used as the housing of the cables. 
Other feature such as heartbeat sensor and GPS allow the workers' health to be tracked to prevent serious dangerous in a large construction and manufacturing site. The heartbeat sensor and GPS are embedded in the safety jacket. The material of the safety jacket intends to reduce the weight of the safety jacket and gives comfort to the wearer. This passive skeletal safety jacket also will be equipped plastic strips at the back of the jacket. The plastic straps incorporate a pad that sits between the shoulder blades, against the thoracic spine and a pad positioned at the lumber spine. The function of the pad is to provide postural feedback by pressing against the spine when the users flexes the torso which reminding the user to maintain an erect torso. The plastic strip is designed to be flexible so that the wearer can adjust the position of the pad according to their upper limb height.

\section{Conflict Of Interests}

On behalf of all authors, the corresponding author states that there is no conflict of interest.

\section{References}

Aker, D., \& Day, G. (1990). Marketing Research(4th edition). New York : Wiley.

Affandi, M., Raemy, M., Ismail, A., Mohamed, F., \& Jafri, M. (2012). Demographic Analysis of Musculoskeletal Disease Occurrence among Industrial Worker's in Malaysia. Jurnal Teknologi (Science and Engineering), 85-88.

Ceylo, S., Morris, D., Lau, K., Diamond, D., \& Moyna, N. (2009). Textile-based wearable sensors for assisting sports performance. IEEE, 307-311.

Cheng, T., Migliaccio, G., Teizer, J., \& Gatti, U. (2012). Data fusion of real-time location sensing and physiological status monitoring for ergonomics analysis of construction workers. 320335.

Chong, H. Y., \& Low, T. S. (2014). Accidents in Malaysian Construction Industry: Statistical Data and Court Cases. Internal Journal of Occupational Safety and Ergonomics, 20:3, 503-513.

Enstzel, P., Albers, J., \& Welch, L. (2006). Best Practices for Preventing Musculoskeletal Disorder in Masonry : Stakeholder Perspectives. Proceedings of the International Congress on Occupational Health. Milan, Italy.

Friedman, E. (2015). Using wearable tech for workplace safety.

Hamid, A. A., Majid, M. A, \& Singh, B. (2008). Causes of Accidents at Construction Sites. Malaysian Journal of Civil Engineering, 242 - 259.

Halim, I., Abdullah, R., \& Ismail, A. (2012). A Survey on Work-related Musculoskeletal Disorder (WMSDs) among Construction Workers. Journal Occupational Safety \& Health 9, 15-20.

Holmstrom, E., Moritz, E., \& Engholm, U. (1995). Musculoskeletal Disorder in Construction Workers, Occupational Medicine : State of Art.

International Labor Organisation (ILO). (2000). Retrieved from Chemical Safety in Asia: Law and Practise: http://www.ilo.org./public/english/protection/saf

Lop, N., Kamar, I., Aziz, M., Abdullah, L., \& Akhir, N. (2017). Work-related to musculoskeletal disorder amongst Malaysian construction trade workers: Bricklayers.

MacDonald, M., Lipscomb, H., Bondy, J., \& Glazner, J. (2009). Safety is everyone's job : The key to safety on a large university construction site. 53-61.

Mahbub, R. (2015). An investigation into the barriers to the implementation of automation and robotics technologies in the cosntruction industry.

Mann, S. (1996). "Smart clothing": Wearable multimedia computing and "personal imaging" to restore the technological balance between people and their environments. In 
Proceedings of the Fourth ACM International Conference on Multimedia, (pp. 163-174). Boston,USA.

Misnan, M., \& Mohammed, A. (2007). Development of safety culture in the construction industry: the leadership roles. Proceedings of International Conference on Ergonomics 2007, (pp. 317-322). Kuala Lumpur.

Rwamamara, R. (2005). The Healthy Construction Workplace : Best Practices in The Swedish Cosntruction Industry to Prevent Musculoskeletal Disorder among Cosntruction Workers. Shamsudin, M. Z., Vijayakumar, V., \& Md Daud, M. Y. (2017). Work-Related Musculoskeletal Disorders (Wmsds) Among Industrial Packaging Workers In Malaysia. Malaysian Journal of Human Factors and Ergonomics, 17-24.

Slyper, R., \& Hodgins, J. (2008). Action capture with accelerometers. In Proceeding of the 2008 ACM SIGGRAPH. Eurographics Symposium on Computer Animation (pp. 193-199). Eurographic Association.

Smallwood, J. (2000). The Influence of Design on Construction Ergonomics: Management and Worker Perceptions. In Proceedings of the Designing for Safety and Health Conference. London.

SOCSO. (2015). Statistics Report about the numbers of accidents by industry year 2016. Retrieved from Social Security Organisation Malaysia.

Stavenich, R., \& Hsio, H. (1996). Injuries and Ergonomic application in construction. Ergonomics Theory and Application Journal, 545-568.

Turner, M., \& lingard, H. (2014). Improving Workers Health in Projects Based Work : Job Security Consideration. Internal Journal of Managing Projects in Business, Vol 9:606-623. 